\title{
Clay as a dispersion agent in anode catalyst layer for PEMFC
}

\author{
Yi-Hao Pai ${ }^{\text {a }}$, Jyh-Harng Ke ${ }^{\mathrm{b}}$, Chih-Cheng Chou ${ }^{\mathrm{c}}$, Jiang-Jen Lin ${ }^{\mathrm{d}}$, \\ Jyh-Myng Zen ${ }^{b, *}$, Fuh-Sheng Shieu ${ }^{\mathrm{a}, *}$ \\ ${ }^{a}$ Department of Materials Engineering, National Chung Hsing University, Taichung 40227, Taiwan \\ ${ }^{\mathrm{b}}$ Department of Chemistry, National Chung Hsing University, Taichung 40227, Taiwan \\ ${ }^{c}$ Department of Chemical Engineering, National Chung Hsing University, Taichung 40227, Taiwan. \\ ${ }^{\mathrm{d}}$ Institute of Polymer Science and Engineering, National Taiwan University, Taipei 10617, Taiwan
}

Received 1 August 2006; received in revised form 6 September 2006; accepted 15 September 2006

Available online 27 October 2006

\begin{abstract}
We report here a hybrid support that substantially improves the dispersion of nanoparticles with different geometric shapes. Without the addition of any organic dispersant, the plate-like clays effectively disperse spherical carbon black (CB) particles in pulverized powder and 5 wt.\% Nafion co-solvent suspension. Fine dispersion of CB particles with an average diameter of 40-60 nm was achieved from the SEM morphology analyses. A $20 \mathrm{wt} . \%$ Pt catalyst was then prepared with various weight ratios of CB/clay hybrids by using the impregnation method and TEM studies confirmed the fine dispersion of Pt nanoparticles with an average diameter of 4-5 nm. Polarization measurements verified that by applying an appropriate quantity of clay modules in preparing anode catalyst layer can indeed enhance the fuel cell performance. In other words, we employed clay to improve the dispersion of $\mathrm{CB}$ and, in turn, to increase catalyst utilization in PEMFC.
\end{abstract}

(C) 2006 Elsevier B.V. All rights reserved.

Keywords: Carbon black; Clay; Catalyst; Dispersion; Fuel cell

\section{Introduction}

Homogeneous dispersion of carbon black (CB) nanoparticles is academically challenging and industrially important in various applications, especially in the field of proton exchange membrane fuel cell (PEMFC) [1-4]. Catalytic support is essential for the development of PEMFC as a high surface area and good electronic property catalytic support can help to improve the utilization efficiency of catalyst materials [5]. Note that the catalyst layer of a PEMFC is mainly made of catalyst material (normally platinum or platinum alloys [6]) and catalytic support (CB [6,7]). Consequently, a fine dispersion process for CB catalytic supports can reduce the amount of Pt in catalyst layer and hence decreases the cost of production. Nowadays the preparing process of such a suspension is tedious with the requirement of CB surface modification and organic dispersing agents, such as surface grafting with copolymers to stabilize CB particles

\footnotetext{
* Corresponding authors. Tel.: +886 42285 4563; fax: +886 422857017 .

E-mail addresses: jmzen@dragon.nchu.edu.tw (J.-M. Zen), fsshieu@dragon.nchu.edu.tw (F.-S. Shieu).
}

[3] and alternation of CB organophilic property by adding an encapsulating agent or surfactant [8]. On the other hand, singlewall carbon nanohorns [9] and carbon nanotubes [10,11] were also reported to increase the catalyst materials surface area to improve the utility of catalyst materials. These catalytic supports, however, require strict processing conditions and tedious operation procedures to effectively use most of the available electrode space and so to cut down the cost [12].

Here, we report a new approach for dispersing CB nanoparticles by introducing clay to prolong the dispersion stability. Two different geometrical shapes of spherical CB and plate-like clay nanoparticles can mutually counteract with their individual particles via the van der Waals force. The self-aggregation of CB particles can then possibly be minimized through the interaction with the plate-like clays. Furthermore, the hydrophilic nature of ionic clay can also render the neutral nanoparticles dispersible in solvent in the absence of any organic dispersants. Overall, the goal of this study is to employ clay to improve the dispersion of $\mathrm{CB}$ and, in turn, to increase catalyst utilization in PEMFC. Polarization measurements were finally studied to evaluate the effect of clay modules in preparing anode catalyst layer to the fuel cell performance. 


\section{Experimental}

\subsection{Catalytic support preparation}

Sodium montmorillonite (MMT, Nancor), carbon black (Vulcan ${ }^{\circledR}$ XC-72, Cabot) and 5 wt.\% Nafion (Du Pont) were used to prepare the catalytic support. The schematic description of the plate-like clays in mixing with $\mathrm{CB}$ particles is shown in Fig. 1. Typical experimental procedures for pulverizing two powder materials are described as follows. Both $\mathrm{CB}$ and clay powder in the designated $\mathrm{CB} /$ clay weight ratios of $100 / 0,85 / 15,67 / 33$ were first physically mixed with the addition of $5 \mathrm{wt} \%$ Nafion co-solvent. They were then agitated by stirring for $30 \mathrm{~min}$ and finally subjected to an ultrasonic generator for further agitation at $30-40{ }^{\circ} \mathrm{C}$ for $5-6 \mathrm{~h}$ until completely swollen.

\subsection{Membrane electrode assembly preparation}

By using the finely dispersed CB particles, a $20 \mathrm{wt} . \% \mathrm{Pt}$ catalyst was prepared by the impregnation method [13] with chloroplatinic acid as metal precursor (Seedchem) on different $\mathrm{CB} /$ clay weight ratio of $100 / 0,85 / 15$, and $67 / 33$ (the loading of the Nafion solution was 5 wt.\%). Note that the catalyst ink (i.e., $\mathrm{Pt} / \mathrm{CB}$ to Nafion solution) ratio used in this study was based on the value reported earlier [14].

To evaluate the effect of clay modules in preparing anode catalyst layer to the fuel cell performance, three samples of MEA were prepared in the present study: (1) $20 \mathrm{wt} . \%$ $\mathrm{Pt}$ in $\mathrm{CB} /$ clay $=100 / 0$ support for anode and cathode, (2)
Clay

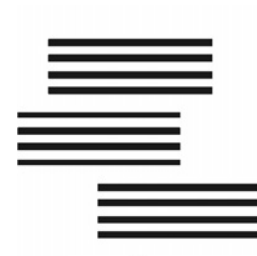

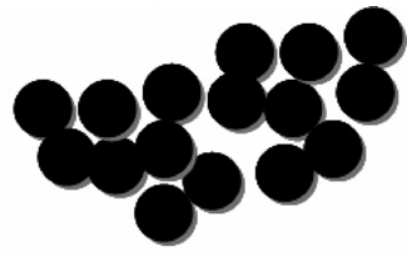

Carbon Black

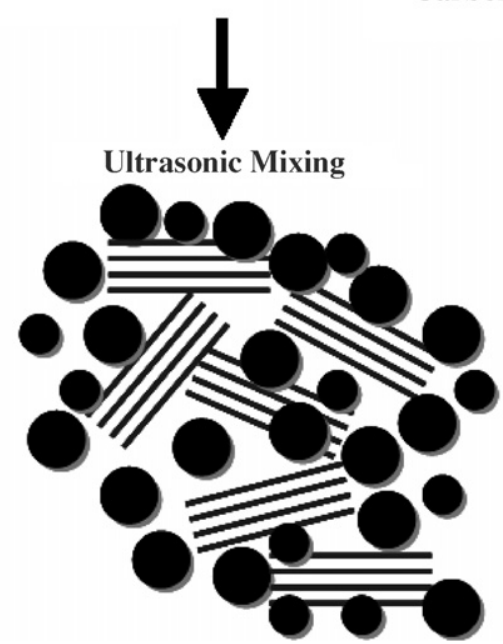

Fig. 1. Schematic description of the homogeneous dispersion of carbon black (CB) in the presence of plate-like clays.
20 wt.\% Pt in CB/clay $=85 / 15$ support for anode and $20 \mathrm{wt} . \%$ $\mathrm{Pt}$ in $\mathrm{CB} /$ clay $=100 / 0$ support for cathode, and (3) $20 \mathrm{wt} . \%$ $\mathrm{Pt}$ in $\mathrm{CB} / \mathrm{clay}=67 / 33$ support for anode and $20 \mathrm{wt} . \% \mathrm{Pt}$ in $\mathrm{CB} /$ clay $=100 / 0$ support for cathode. Details of the preparation procedure of MEAs are described as follows. The catalyst ink was first coated onto one side of a $5 \mathrm{~cm}^{2}$ Nafion 112 (Du Pont) polymer electrolyte membrane (PEM) $[15,16]$ and then dried at $80^{\circ} \mathrm{C}$ in vacuum $\left(10^{-2}\right.$ Torr $)$ for $30 \mathrm{~min}$. Another side of the membrane was treated similarly after the first side of the PEM was dried. The PEM was sandwiched between two layers of catalyst ink to serve as anode and cathode and the anode/PEM/cathode module was used as the MEA in polarization measurements. Note that the Pt loading was kept at a constant value of $0.4 \mathrm{mg} / \mathrm{cm}^{2}$ in the catalyst ink.

\subsection{Carbon black/clay hybrids characterization and fuel cell polarization}

Surface analysis of the catalytic supports was studied by using a JEOL 6700F SEM. The liquid water contact angle (WCA) at the surface of $\mathrm{CB} /$ clay was measured with the sessile-drop method by using a contact angle system FTA 200 (ACIL \& First Ten Angstroms Inc.). Three samples with at least three spots per $\mathrm{CB} /$ clay were measured. The MEA polarization curves were carried out at a fuel cell system (BEAM ASSOCIATE CO., LTD) with the reactant (hydrogen and oxygen) streams being kept at a water vapor saturation temperature of $50{ }^{\circ} \mathrm{C}$ with a flow rate of $100 \mathrm{sccm}$. Temperature of the single cell was kept at $60^{\circ} \mathrm{C}$ throughout the test. The microstructure and crystalline phase analysis were studied by a using a Zeiss 902 A TEM through the comparison of selected area diffraction (Zeiss 902 A TEM, SAD) patterns of the catalyst ink with those of standard compounds reported in the JCPDS Data File.

\section{Results and discussion}

\subsection{Characterization of the catalytic supports}

The surface morphology of catalytic supports (i.e., CB/clay weight ratios at 100/0,85/15, and 67/33) were first examined by using an FE-SEM instrument. As can be seen in Fig. 2a, the control experiment with pure $\mathrm{CB}$ shows a serious aggregation effect with an average size of $100-300 \mathrm{~nm}$ in diameter. It appears that the $\mathrm{CB}$ powder can aggregate easily from the pristine structure of irregular spherical shape in average diameter of 40-60 nm. In general, it is the van der Waals force among nanoparticles to cause the aggregation of CB particles. The aggregation can thus occur during the preparation process since the $\mathrm{CB}$ power cannot be completely dispersible in solvent. Actually the formed precipitates can easily be noticed even by naked eyes. Interestingly, with the addition of clay, the $\mathrm{CB}$ /clay hybrid turns out to be dispersible in solvent by subjecting to an ultrasonic process (Fig. 2b and c). It is expected that the geometric structure of the pristine MMT clay with a well-defined structure of the primary units consisting of aluminosilicate platelets in stacks to improve the dispersion. The irregularly shaped unit platelets were esti- 

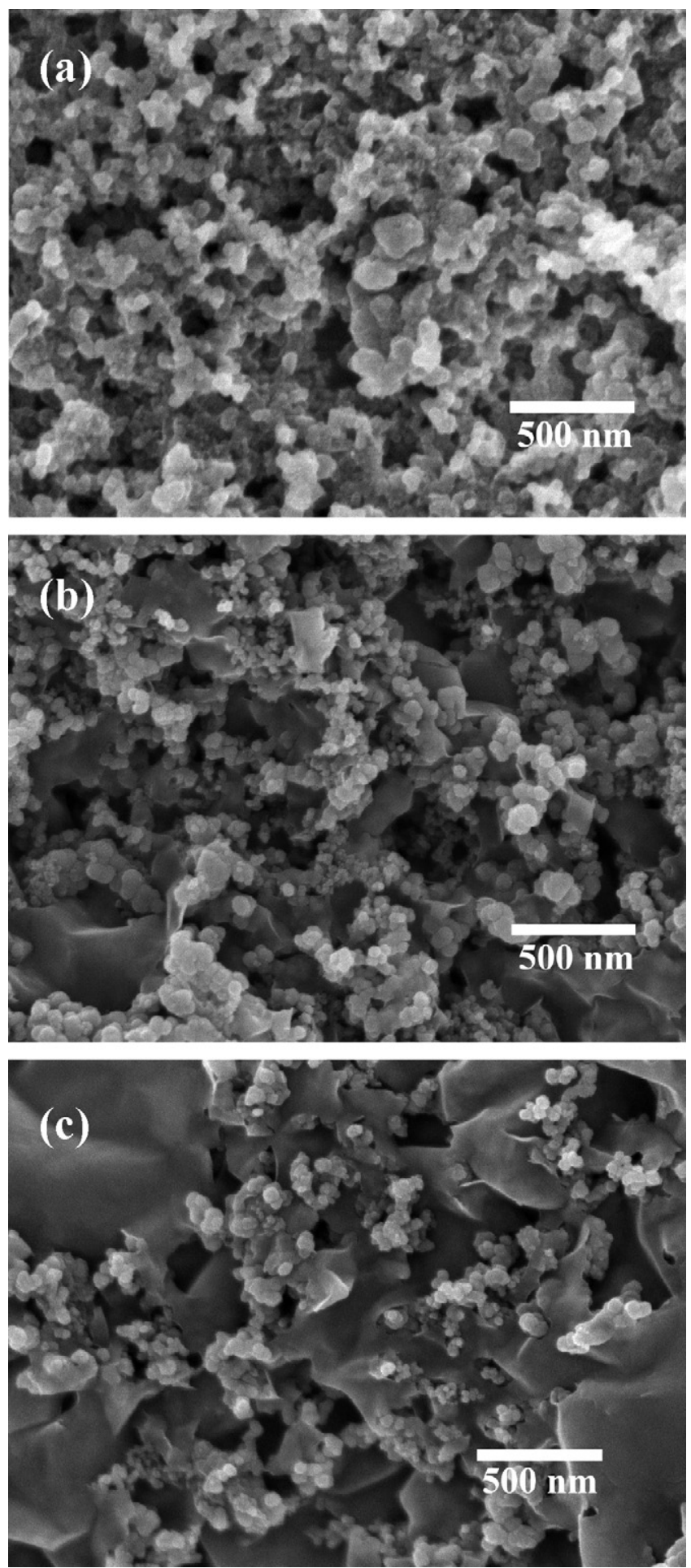

Fig. 2. FE-SEM images of (a) $\mathrm{CB} / \mathrm{clay}=100 / 0$, (b) $\mathrm{CB} / \mathrm{clay}=85 / 15$, and (c) $\mathrm{CB} /$ clay $=67 / 33$.

mated to be $100 \mathrm{~nm} \times 100 \mathrm{~nm} \times 1 \mathrm{~nm}$ for MMT $[17,18]$. Due to the intensive ionic charge character, these clays are hydrophilic and swelling in solvents. As can be seen in Fig. $2 b$ and $c$, the dispersion of $\mathrm{CB}$ is very effective in the presence of clay with an average particle size of $\sim 40-60 \mathrm{~nm}$.

The improvement in the hydrophilic property of the hybrid material was further studied. Fig. 3 shows the results observed (a)

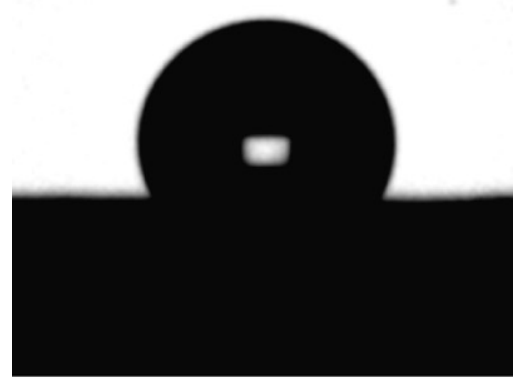

(b)
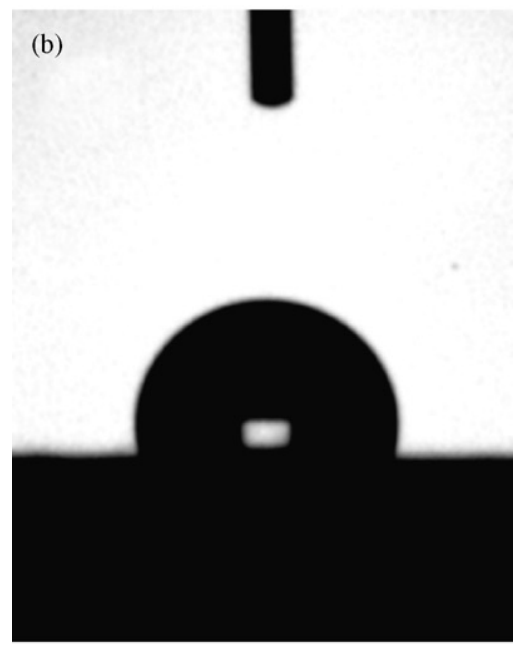

(c)
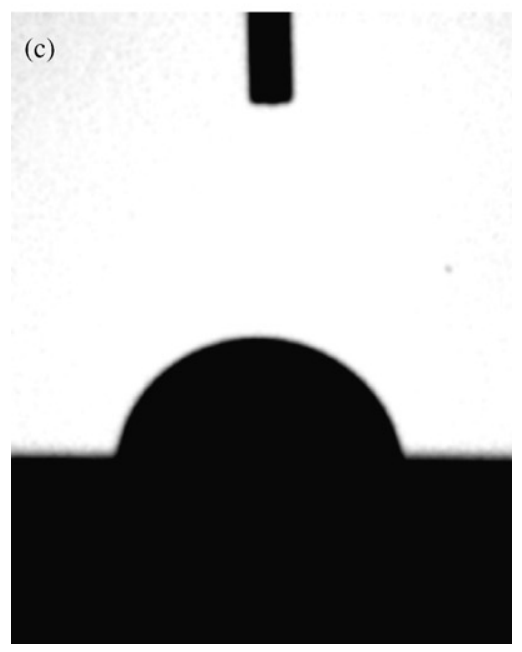

Fig. 3. Sessile-drop test for the (a) $\mathrm{CB} / \mathrm{clay}=100 / 0$, (b) $\mathrm{CB} / \mathrm{clay}=85 / 15$, and (c) $\mathrm{CB} / \mathrm{clay}=67 / 33$.

from the sessile-drop test. The water contact angles (WCA) for the $\mathrm{CB} / \mathrm{clay}$ surface are $130.0^{\circ}, 110.4^{\circ}$ and $90.6^{\circ}$ for the clay addition at 0,15 , and $33 \mathrm{wt} \%$, respectively. Apparently, the wettability of the catalytic supports was effectively improved in the presence of the clay component. 

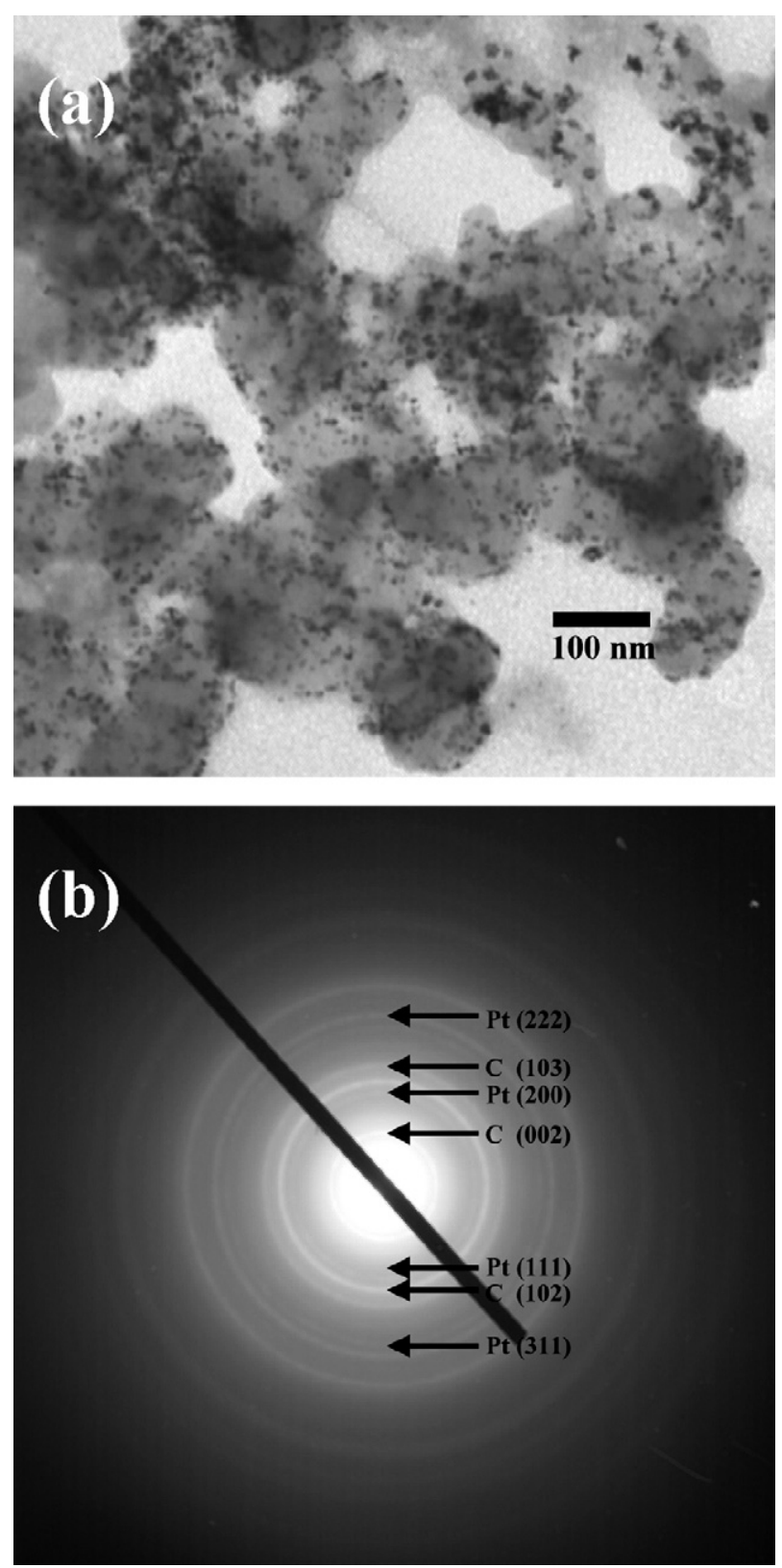

Fig. 4. Bright field images (a) and SAD patterns (b) of the $20 \mathrm{wt} . \%$ catalyst ink $(\mathrm{CB} / \mathrm{clay}=85 / 15)$ material prepared by the impregnation method.

\subsection{Microstructure and crystalline phase of catalytic ink}

Fig. 4a illustrates the bright field morphology of the $20 \mathrm{wt} . \%$ catalyst ink $(\mathrm{CB} / \mathrm{clay}=85 / 15)$ material. As can be seen, the $\mathrm{Pt}$ and $\mathrm{CB}$ particles appear in different contrast levels in the TEM microstructure. It is expected that the high- $\mathrm{Z}$ region (i.e., high mass region) may scatter more than the low- $Z$ region of a given sample with a constant thickness throughout [21]. Therefore, the $\mathrm{Pt}$ region or high- $\mathrm{Z}$ region on the sample exhibits a higher contrast, and vice versa for the CB particles. Fig. 4a also reveals a homogeneous distribution of Pt particle (with an average particle diameter of $5 \mathrm{~nm}$ ) on the catalytic support by using the impregnation method. From the obtained SAD patterns (Fig. 4b), the
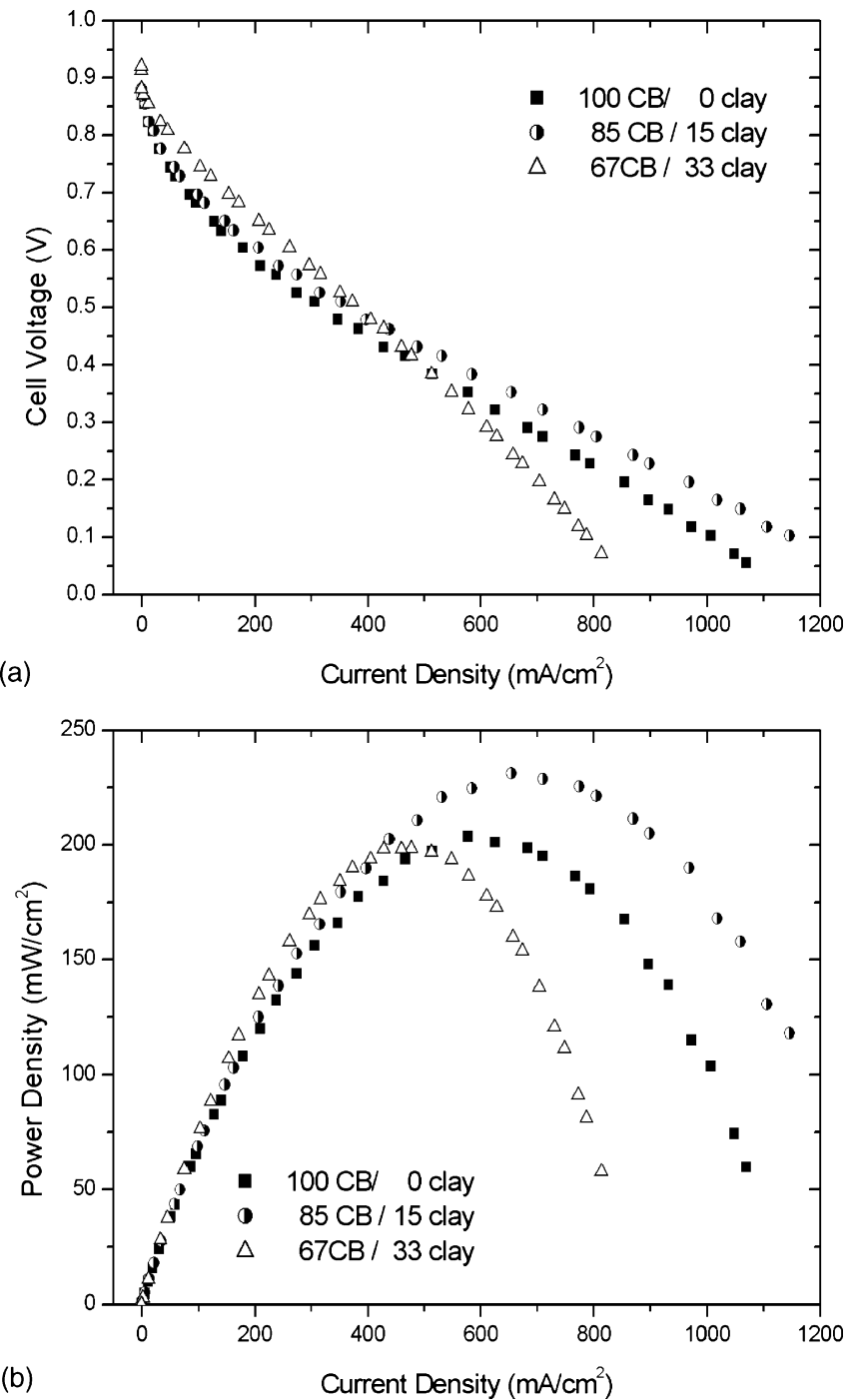

Fig. 5. Cell voltage vs. current density curves (a) and power density vs. current density curves (b) of MEAs with various $\mathrm{CB}$ /clay weight ratios.

$d$ spacing was measured as $2.265 \AA$ for the (1 111$)$ reflection of the Pt phase.

\subsection{Membrane electrode assembly performance in single cell test}

Fig. 5a shows the results of polarization test ( $V-I$ plot). As can be seen, for the three assembling cases mentioned above, the open circuit voltages (OCV) are all observed at $\sim 0.89 \mathrm{~V}$. The reversible potential of the fuel cell electrochemical reaction is $1.2 \mathrm{~V}$ at standard condition for PEMFC. The actual voltage is lower than the theoretical value due to the irreversible losses [19]. It is found that the MEA with the $\mathrm{CB} /$ clay $=85 / 15$ shows the widest ohmic polarization range of $50-1150 \mathrm{~mA} / \mathrm{cm}^{2}$, which is a little bit larger the other two cases of $\mathrm{CB} /$ clay $=100 / 0$ and $\mathrm{CB} / \mathrm{clay}=67 / 33$. These indicate that the clay addition can indeed significantly improve the ohmic polarization [20]. In addition, the polarization curves start to be affected by the mass transport limitation at much higher cur- 
rent densities. In other words, an appropriate addition of clay can improve wettability and hydrophilic property of anode. The power density to current density diagram $(P-I$ plot $)$ is shown in Fig. 5b. The MEA with $\mathrm{CB} / \mathrm{clay}=85 / 15$ shows an optimal power output of $230 \mathrm{~mW} / \mathrm{cm}^{2}$ with a current density of $670 \mathrm{~mA} / \mathrm{cm}^{2}$. The values are greater than those of the MEA with $\mathrm{CB} /$ clay $=100 / 0$ case $\left(200 \mathrm{~mW} / \mathrm{cm}^{2}, 570 \mathrm{~mA} / \mathrm{cm}^{2}\right)$ and MEA with $\mathrm{CB} /$ clay $=67 / 33$ case $\left(200 \mathrm{~mW} / \mathrm{cm}^{2}, 470 \mathrm{~mA} / \mathrm{cm}^{2}\right)$. Note that the quantity of clay modules in preparing the anode catalyst layer does not represent an optimum composition. The purpose of the study is to verify that by applying an appropriate quantity of clay modules in preparing anode catalyst layer can indeed enhance the fuel cell performance. Nevertheless, the addition of non-conducting MMT deteriorated the PEMFC performance due to the increase in ohmic loss as indicated in Fig. 2c when the volume ratio of MMT is too large. This disadvantage will eventually limit its application in PEMFC.

\section{Conclusion}

We have developed a novel method in the absence of organic dispersants for homogeneous dispersion of CB in $5 \mathrm{wt}$ \% Nafion co-solvent suspension by using platelet-like clays. The geometric heterogeneity allows the $\mathrm{CB} /$ clay hybrid to form a stable dispersion in 5 wt.\% Nafion co-solvent suspension. Furthermore, the hydrophilic properties of the catalytic supports were effectively improved by using clay materials. The water contact angles $(\mathrm{WCA}$ ) for the $\mathrm{CB} / \mathrm{clay}=100 / 0, \mathrm{CB} / \mathrm{clay}=85 / 15$, and $\mathrm{CB} / \mathrm{clay}=67 / 33$ were measured as $130.0^{\circ}, 110.4^{\circ}$, and $90.6^{\circ}$, respectively. Additionally, the polarization and power density of the MEA was indeed improved. TEM images also reveal a homogeneous Pt particle distribution (average particle diameter of $5 \mathrm{~nm}$ ) on the catalytic support. Results show that the MEA with an appropriate quantity of clay modules in preparing anode catalyst layer can indeed enhance the fuel cell performance.

\section{Acknowledgements}

The work is financially supported by the National Science Council (NSC) of Taiwan through grants NSC-094-2218-E-005007 and NSC-95-ET-7-005-003-ET. The authors would also like to thank Mr. Wen-Kai Chao for his assistance in measuring liquid water contact angle.

\section{References}

[1] Y. Zhang, C. Erkey, Ind. Eng. Chem. Res. 44 (2005) 5312.

[2] D.R. Rolison, K.E. Swider, Langmuir 15 (1999) 3302.

[3] H.Y. Li, H.Z. Chen, J.Z. Sun, J. Cao, Z.L. Yang, M. Wang, Macromol. Rapid Commun. 24 (2003) 715.

[4] F. Tiarks, K. Landfester, M. Antonietti, Macromol. Chem. Phys. 202 (2001) 51.

[5] P. Yu, M. Pemberton, P. Plasse, J. Power Sources 144 (2005) 11.

[6] S. Srinivasan, O.A. Velev, A. Parthasarathy, D.J. Manko, A.J. Appleby, J. Power Sources 36 (1991) 299.

[7] S. Litster, G. McLean, J. Power Sources 130 (2004) 61.

[8] H. Spinelli, Adv. Mater. 10 (1998) 1215.

[9] T. Yoshitake, Y. Shimakawa, S. Kuroshima, H. Kimura, T. Ichihashi, Y. Kubo, D. Kasuya, K. Takahashi, F. Kokai, M. Yudasaka, S. Iijima, Physica B 323 (2002) 124.

[10] H. Hou, D.H. Reneker, Adv. Mater. 16 (1) (2004) 69.

[11] C. Wang, M. Waje, X. Wang, J.M. Tang, R.C. Haddon, Y. Tan, Nano Lett. 4 (2) (2004) 345.

[12] C.C. Chen, C.F. Chen, C.H. Hsu, I.H. Li, Diam. Relat. Mat. 14 (2005) 770.

[13] S.R. de Miguel, J.I. Vilella, E.L. Jablonski, O.A. Scelza, C.S.-M. de Lecea, A. Linares-Solano, Appl. Catal. A-Gen. 232 (2002) 237.

[14] L. Xiong, A. Manthiram, Electrochim. Acta 50 (2005) 3200.

[15] M. Wilson, S. Gottesfeld, J. Electrochem. Soc. 139 (1992) 28.

[16] Y.G. Chun, C.S. kim, D.H. Peck, D.R. Shim, J. Power Sources 71 (1998) 174.

[17] M. Alexandre, P. Dubois, Mater. Sci. Eng. 28 (2000) 1.

[18] J.J. Lin, Y.M. Chen, Langmuir 20 (2004) 4261.

[19] M. Gangeri, G. Centi, A. La Malfa, S. Perathoner, R. Vieira, C. Pham-Huu, M.J. Ledoux, Catal. Today 102-103 (2005) 50.

[20] U.H. Jung, K.T. Park, E.H. Park, S.H. Kim, J. Power Sources 159 (1) (2006) 529.

[21] D.B. Williams, C.B. Carter, Transmission Electron Microscopy, Plenum, New York, 1996, pp. 351-354. 